\title{
Sobre magos y anteojeras
}

Cuando era un estudiante universitario y escuchaba la palabra "finanzas", solían venirme a la cabeza por asociación libre algunas otras que, dado que no terminaba de comprenderlas muy bien, tenían un halo de misterio que encontraba fascinante: valorización, riesgo, opciones, derivados. Hoy en día, la misma palabra evoca en el gran público otra, igual de fascinante, pero con un cariz algo conminatorio: ética. Uno de los investigadores que más destaca, a propósito de la relación entra una y otra, es el profesor John Hendry, autor del libro "Ethics and Finance: An Introduction". En otro artículo, el mismo autor comenta acerca de la muy mala reputación de las finanzas debido al comportamiento, ya no solamente inmoral sino también ilegal, de los practicantes de la disciplina. Esta mala fama, afirma Hendry, tiene importantes componentes de ignorancia y de prejuicio, este último muy enraizado en nuestra cultura y tradición. (Hendry, 2015). Al respecto veamos.

En el mundo judeocristiano, la usura tradicionalmente ha cargado con un estigma que encuentra su sustento en comentarios específicos que encontramos en la Biblia. Por ejemplo, en el Antiguo Testamento, Ezequiel afirma que, quien "presta con interés y exige con usura; ¿vivirá? ¡No vivirá!" (Ezequiel 18:13), mientras que, en el Nuevo Testamento, con mayor mesura y elocuencia, pero con idéntica perspectiva crítica, leemos que "Si prestáis a aquellos de quienes esperáis recibir, ¿qqué mérito tenéis? También los pecadores prestan a los pecadores para recibir de ellos la misma cantidad. Antes bien, amad a vuestros enemigos, y haced bien, y prestad no esperando nada a cambio" (Lucas 6:34, 35). La legislación eclesiástica se mantuvo firme en esta línea: En 325, en el Concilio de Nicea, se acordó y promulgó la prohibición a los clérigos de prestar con intereses ${ }^{1}$, prohibición que incluiría oficialmente a los laicos en el siglo XII ${ }^{2}$. Esta posición de la Iglesia se mantuvo inalterada por mucho tiempo: en fecha tan tardía como 1515, podemos encontrar que, durante el Quinto Concilio de Letrán y al referirse a la usura, se la define como "la adquisición de la ganancia y el beneficio sin ningún tipo de trabajo, cualquier gasto o riesgo alguno" ${ }^{3}$. Los especialistas afirman que, recién a mediados del siglo XVII, la usura pasó a ser definida no como el cobro de cualquier tipo de interés sino como el cobro excesivo del mismo, dando pie a que se relajara un poco la posición en contra de quienes se dedican al negocio del financiamiento. A pesar de ello, la trampa sigue vigente, dada la subjetividad del término "excesivo" que, automáticamente, despierta en algunos el afán regulador e intervencionista característico de ciertas posiciones políticas, no por contemporáneas menos trasnochadas.

Esta tradicional mala fama que acarrea una actividad tan fundamental para la economía como es la intermediación financiera, ha terminado extendiéndose a las diversas áreas de las finanzas. Que el campo se haya tecnificado de tal manera que se haya convertido en algo ininteligible y arcano para el neófito, no contribuye a una mejoría en su imagen: los financistas pueden, sin duda, ser vistos como nigromantes de cuello blanco y corbata de diseñador, poseedores de ciertos conocimientos iniciáticos que practican en la soledad de sus nuevas Isengard y Orthanc ${ }^{4}$ de Wall Street, y que como todos sabemos han de corromper a quienes profundicen demasiado

\footnotetext{
${ }^{1}$ Canon XVII promulgado en el Primer Concilio de Nicea: 20 de mayo a 19 de junio de 325

${ }^{2}$ Segundo y Tercer Concilios de Letrán, 1139 y 1179 respectivamente

${ }^{3}$ En la décima sesión, celebrada el 04 de mayo de 1515, al tratar la reforma de los Montes de Piedad

${ }^{4}$ Isengard es una fortaleza y Orthanc una torre, en las que practicaba sus artes el mago Saruman el Blanco, en la Tierra Media de J.R.R. Tolkien
} 
en ellos. Y la prueba de esta perla de sabiduría popular estaría a la vista de todo aquel que quiera revisar las noticias: fraudes financieros que derivan en quiebra de empresas y en crisis internacionales de las que, luego, es tan difícil salir.

El profesor Hendry tiene una posición interesante, y no poco controversial, al respecto. Él argumenta que los problemas éticos que aquejan a las finanzas no deben ser achacados, en principio, a un mal comportamiento intencional. Los actos que hoy reconocemos como objetables y reprensibles, afirma, en su momento no fueron vistos como tales por quienes los cometieron, sino en cambio como una suerte de estiramiento, de elongación sin ruptura de las normas y, en particular, de las normas técnicas contables y tributarias. En ningún momento se puso sobre la mesa la implicancia y valoración de tales actos en un marco de referencia ético. Es decir, se erró sin duda, pero no hubo dolo. Al menos, concluye, no en la mayoría de los casos.

El actuar de los profesionales de las finanzas se debe entender teniendo en cuenta una característica del dinero que muchas veces se pasa por encima. Establezcamos primero un punto de partida con el que podamos todos estar de acuerdo, y es que la función esencial de las finanzas es la asignación eficiente de los recursos financieros en la economía. Sin embargo, aparentemente en los últimos 30 años los agentes financieros no han estado haciendo exactamente eso. Hendry afirma que el principal resultado, o al menos el más evidente, de la labor de los principales agentes financieros ha sido la "extracción" de recursos: no solo se han enriquecido más que el resto de agentes económicos, sino que lo han hecho a expensas de ellos. ¿Son por ello los profesionales de las finanzas intrínsecamente inmorales? ¿son menos éticos que los profesionales de otros sectores? La respuesta es no, y la explicación propuesta va por el lado de que existiría una suerte de incompatibilidad esencial entre la gestión del dinero y el sentido ético en nuestras sociedades.

Las empresas, al producir bienes o servicios, están expuestas directamente a los juicios éticos de la sociedad en la que se desarrollan, ya que dichos bienes o servicios tienen un impacto directo en la reputación de las empresas y esta reputación está alineada con los valores de la comunidad. Un producto o un servicio será juzgado por una sociedad particular según su patrón de valores, su moral particular. Hendry propone que el dinero, a diferencia de cualquier producto o servicio, tiene un alcance global y trasciende las fronteras, los patrones culturales y las estructuras de valores de las sociedades. En este contexto, el dinero sería culturalmente neutral y, al estar disociado de los valores de una cultura en particular, cualquiera que esta sea, termina estando disociado de la ética en general. Esta disociación repercutiría en un relajamiento del imperativo moral de los agentes financieros, en un aturdimiento temporal de su sentido ético.

Esta relación entre el dinero y el relajamiento del imperativo moral en las personas ya ha sido documentada en la literatura científica. Un trabajo de investigación desarrollado por Kouchaki, M., Smith-Crowe, K., Brief, A. P., \& Sousa, C. (2013) mostró que aquellos participantes, que fueron inicialmente expuestos a conceptos y situaciones relacionadas con dinero, mostraron luego una mayor propensión hacia conductas no éticas. El estudio encontró evidencias de que esta relación estaría mediada por la adopción de marcos de decisión que maximizan el beneficio personal, priorizándolo por sobre otras formas de beneficio colectivo. La misma tecnificación del campo que mencionábamos antes, incentivaría esta tendencia a relajar el imperativo moral puesto que, como dice Hendry, la tecnología no solo se presenta a si misma como moralmente neutral, sino que se precia de serlo. 
¿Qué hacer? Hay algunas propuestas, ciertamente, pero ninguna definitiva. En general, como mencionamos antes, se apuesta mucho por el desarrollo de leyes y reglamentos diversos. Sin embargo, en vista de que tales esfuerzos regulatorios no parecen producir los resultados esperados, el profesor Hendry apuesta por una mayor profesionalización, más educación y mejor entrenamiento para los agentes financieros. Concuerdo. Una mejor comprensión del fenómeno, de sus causas y consecuencias, a través de la educación y profesionalización de los agentes financieros, debería contribuir a mantenerlos alerta para identificar primero, y evitar después, los errores de juicio y lapsos éticos que terminan ocupando las portadas de los diarios y las sentencias de los tribunales.

Referencias:

Hendry, John (2013). Ethics and finance: An introduction. Cambridge, England: Cambridge University Press.

Hendry, John (2015). Ethics in Finance - Why is it such a problem? The European Financial Review, (October-November). Retrieved from http://johnhendry.co.uk/wp/wpcontent/uploads/2015/10/Ethics-in-Finance-Why-is-it-such-a-problem.pdf

Kouchaki, M., Smith-Crowe, K., Brief, A. P., \& Sousa, C. (2013). Seeing green: Mere exposure to money triggers a business decision frame and unethical outcomes. Organizational Behavior and Human Decision Processes, 121(1), 53-61. https://doi.org/https://doi.org/10.1016/j.obhdp.2012.12.002 